\title{
Application of Modified Ventilator Bundle and Its Effect on Weaning Among Mechanically
}

\author{
Ventilated Patients
}

\author{
Amany Sayed Eweas ${ }^{1}$, Sahar Yassien Mohammad ${ }^{2}$, Jehan Sayyed Ali Sayyed ${ }^{3}$, Marwa Mohammad Abd Elbaky ${ }^{4}$ \\ and Magda Mohammad Bayoumi ${ }^{5}$
}

(1) Clinical Instructor in Faculty of Nursing, Bani Suief University, Egypt.

(2) Prof. in Medical Surgical Nursing, Faculty of Nursing, Ain Shams University, Egypt.

(3) Prof. in Medical Surgical Nursing, Faculty of Nursing, Minia University, Egypt.

(4) Lecturer in Medical Surgical Nursing, (Critical Care Nursing), Faculty of Nursing, Minia University, Egypt.

(5) Lecturer in Medical Surgical Nursing, Faculty of Nursing, Bani Suief University, Egypt.

\begin{abstract}
Background: Modified ventilator bundle is a cluster of key interventions deriving from evidence-based clinical practice guidelines that when implemented together are expected to improve patient outcomes and reduced the risk of ventilator associated pneumonia and other related complications common in ventilated patients. Aim: The current study aimed to apply a modified ventilator bundle and evaluate its effect on weaning among mechanically ventilated patients. Design: A quasi- experimental research design was utilized. Setting: This study was conducted at the following critical care units (surgical, medical and cardiac care unites) affiliated to Bani Suief University Hospital in Bani Suief city, Egypt. Subjects: A Purposive sample of $\mathbf{1 0 0}$ mechanically ventilated patients divided into two groups, the study group included patients who received the modified ventilator bundle while the control group included patients who received the routine hospital nursing care. Data collection tools: Two tools were used; First tool patient assessment sheet include two parts, part one: patient demographic and medical characteristic part two: physical assessment record. Second tool: Weaning process assessment checklists by used burns wean assessment program score. Results: The study group of patients obtained higher weaning scores than the control group. As well the study group demonstrated shorter duration of the connection to mechanical ventilation compared to control group. Conclusion: Implementation of modified bundle plays a pivotal role on higher weaning score and reduction of ventilation days. Recommendations: Designing in-service training educational program for critical care nurses to improve nurses' knowledge and practice regarding a modified ventilator bundle. Furthermore, replication of the study on a larger probability sample from different geographical locations in order to generalize the results.
\end{abstract}

Key words: Mechanical Ventilation, Modified Ventilator Bundle, Weaning

\section{Introduction}

Mechanical ventilation (MV) has become the most commonly used modes of life support among critical ill patients in medicine today. Although MV is a life saving intervention, is capable of producing many of the complications, some of which may be a life threatening as ventilator associated pneumonia (VAP).VAP is a lower respiratory tract infection that develops in intubated patients for greater than 48 hours .VAP is the most common infection in ventilated patients and the second most common hospital associated infection that associated with higher mortality rates between $20 \%$ and $70 \%$ and increase hospital lengths of stay from 4-13 days (Ahmed, Sobeih and Abdelsalam, 2019).

Modified ventilator bundle is a series of interventions developed by the institute for healthcare improvement related to ventilator care that, when implemented together, will achieve significantly better outcomes than when implemented individually. Performance of this bundle associated with reduced the incidence of VAP, decrease risk of reintubation or intensive care readmissions, improvement of weaning strategies and optimizes patient recovery, to achieve this goal ventilator bundle includes head of bed elevation $30-45 \%$, peptic ulcer prophylaxis, DVT prophylaxis, endotracheal suctioning care, infection control measures, assess for readiness to stop sedation and to start spontaneous breathing trials, oral care with the chlorhexidine and early mobilization (Mart, Brummel and Ely 2019).
Weaning covers the entire process of liberating the patient from mechanically ventilation support and from endotracheal tube to independent breathing. This process consists of " 3" key steps: first step, when the patient's clinical conditions permit it, ventilation supports are progressively decreased (Ready weaning); second step, a spontaneous breathing trial (SBT) assesses the patient's capability to breathe autonomously (Ready breathing); and third step, the patient is liberated from ventilation support (Ready extubation) The clinical goals of weaning are twofold: first, to promptly identify those patients who are ready to begin the process of weaning, and second, to optimize the weaning regime to reduce the transition time from dependence to independence from MV (Vetrugno, et al., 2020).

In order to ensure optimal care for mechanically ventilated patients, the critical care nurses have a major role in prevention of hospital acquired infections overall and VAP in particular. they can contribute a lot in the prevention of VAP through reducing risk factors, implementing relevant preventive measures, identifying early signs for early and prompt management, Beyond these, ICUs nurses shoude be monitoring of respiratory function, regular monitoring of vital signs for patients to immediate detections of any complications, adequate nutritional support, maintenance of application the "modified ventilator care bundle" and adherence to" weaning protocols (Alsharari. et al., 2020). 


\section{Significance of the Study}

Mechanical ventilation is a life saving intervention; but it poses significant clinical and economic challenges due to the risk of complications. Approximately $30 \%$ of patients treated with MV experience difficult or prolonged weaning process (Kasem, .et al., 2019). Patients who experience difficulty in weaning need a longer hospital stay and have higher morbidity and mortality rate. Consequently, trials to decrease the duration of weaning are desirable to reduce length of MV connection and its related complications. Standardized weaning practices are safe and effective in reducing the time spent on MV. However, the evidence supporting their use in practice is inconsistent. The discordant results of studies may reflect the fact that weaning protocols differ in composition and are implemented in different environments by various health care providers.

Few research studies were conducted nationally on the ventilator bundle practices and its effect on weaning from MV and their findings illustrated that, implementation of modified ventilator bundle practices may enhanced the weaning process, reduce the incidence of such complications, improve the quality of patient care, improve the prognosis of patients condition and this in turn would decrease the average length of ICU stay, decrease long term physical, cognitive, and psychological harm to patients and their family; improve hospital reimbursement and decrease health care costs. Eventually, this research might generate an attention and motivation for further studies in this area.

\section{Aim of the Study:}

The aim of this study is to apply a modified ventilator bundle and evaluate its effect on weaning among mechanically ventilated patients.

\section{Research Hypothesis:}

To fulfill the aim of this study, the following research hypothesis was formulated:-

The study group of patients for whom all elements of the modified ventilator bundle were applied completely would get higher weaning scores and shorter duration of the connection to mechanical ventilation compared to the control group of patients who received the routine hospital nursing care.

\section{Operational Definition}

Modified ventilator bundle are a grouping of best practices supported by research to decrease the rates of VAP and other complications common in ventilated patients. The core elements of bundle are included: head of bed elevation $30^{\circ}-45^{\circ}$, early mobilization, oral care with chlorhexidine, endotracheal suctioning care, daily sedation interruption and daily assessment of readiness to extubate, deep venous thrombosis prophylaxis peptic ulcer prophylaxis, ventilator circuit care and infection control measures.

\section{Research Design:}

A quasi-experimental research design was utilized in the current study. Quasi-experiment is an empirical study used to estimate the causal impact of an intervention on its target population without random assignment. This design according to Usadọlo (2016) can be used to examine the relationship between an independent (cause) and dependent (effect) variables. Therefore, the design is most appropriate to investigate the effect of the modified ventilator bundle on weaning.

\section{Setting:}

The current study was conducted at the following critical care units (surgical, medical and cardiac care unites) affiliated to Bani Suief University hospital in Bani Suief city, Egypt.

\section{Subjects}

A Purposive sample of $\mathbf{1 0 0}$ mechanically ventilated patients were assigned in the current study started from initiation of MV connection till extubate, the patients were matched for their age and medical characteristics and were divided randomly into two equal groups . The first study group $(n=50)$ the patients received the modified ventilator bundle practices completely. The second control group $(n=50)$ the patients received the routine hospital nursing care during MV period. Both groups of the current study were selected according to the following inclusion and exclusion criteria:-

\section{Inclusion Criteria:-}

- The study included patients from both gender and their age (between 20-65).

- Patients with glasgow coma scale more than or equal (9 score)

- Patients on invasive mechanical ventilation.

- No scheduled surgery in the following 72 hours.

Exclusion Criteria Patients were excluded if:

- Patients who have a brain stem infarction

- Patients with neuromuscular diseases

- Patients with multiple organ dysfunction syndrome

- Patients with major cardiac- thoracic or abdominal surgery

- Patient admitted with a chest infection or any other systemic infection

- Patients with acute physiology and chronic health evaluation (APACHE) score over 35.

Sample size: The sample was calculated by using the following equation according to Epi info, version 3.5. Based on confidence level of $95 \%$, power $85 \%$, and $20 \%$ recurrence rate (Krishnappa, et al. 2018)

$$
\mathrm{N}=\frac{\mathrm{t} 2 \times \mathrm{p}(1-\mathrm{p})}{\mathrm{m} 2}
$$

\section{Description:}

- $\mathrm{N}=$ required sample size

- $\mathrm{t}=$ confidence level at $95 \%$ (standard value of 1.960 )

- $\mathrm{p}=$ total no of mechanically ventilated patient's admitted in the previous mentioned ICUs

- $\mathrm{m}=$ margin of error at $5 \%$ (standard value of 0.050 ).

\section{Tools for Data Collection}

To collect data pertinent in the current study, two tools were utilized:-

\section{Tool 1: Patient Assessment sheet:}

This tool was developed by the researcher after revising extensive literature review. It covers two main parts:- 
$1^{\text {st }}$ part: - Patient's Demographic and Medical Characteristic

It consists of (10) items used once for both groups which include the patient's age, gender, marital status, place of residence, occupation, educational level, smoking habits' , date of ICU admission, medical diagnosis and reason of ICU admission

\section{$2^{\text {nd }}$ part: - Physical Assessment Record:-}

It consists of (20) items used once for both study and control groups, which includes patient physical assessment of body systems that include respiratory, cardiovascular and neurological system by used Glasgow coma scale.

\section{Tool II: Weaning Process Assessment Checklist:}

Using Burns Wean Assessment Program score (BWAP) for both studied groups once every day after 72 hours of MV initiation till extubation. This tool adopted from Burns, et al. (1990) and it is used to systematically assess and track weaning progresses of the MV patients. BWAP score, which including (26 items) covering two major areas of the assessment of weaning, the first part is a general assessment, including (12 items) and the second part is respiratory assessment which contains (14 items).

Scoring System BWAP score requires assignment one of 2 responses (yes or no) "Yes "response indicates that the items is present scored "1" while "No" response indicates that the items is not present scored "ZERO". BWAP score is calculated by dividing the total number of yes responses by 26 (the total number of BWAP factors). A cutoff point for the instrument is $50 \%$. If the score was more than or equal $50 \%$, this means that the patients were more likely to be weaned successfully. And if the score was less than 50\%, this indicates that the patients were more likely to have unsuccessful weaning.

\section{Tools Validity and Reliability}

The tools content validity was done to identify the degree to which the used tools measure what was supposed to be measured. Developed tool was examined by a panel of five experts' opinion in the field of critical care medicine and critical care nursing specialty. Tools reliability wares done to identify the extent of tools items were measured with the study concept and its correlation with each other. Cronbach's alpha reliability it was $(0.81)$ for the first tool, $(0.79)$ for the second tool.

\section{Pilot Study}

A pilot study was carried out on $10 \%$ (10 patients) of the total sample of mechanically ventilated patients in the previously mentioned ICUs to test the feasibility of the research process, objectivity, and applicability of the study tools. Based on the results of the pilot study, no modifications were done for data collection tools so; the patients who shared in the pilot study were included in the actual study sample.

\section{Ethical Considerations}

An official permission to conduct the study was obtained from the ethical committee of research, dean of the faculty of nursing at Minia University, directors of the Bani Suief University Hospital, academic for research center and technology. Patients in this study were entirely voluntary who was explained about the aim, purpose, procedure and nature of the study and had the right to refuse of participate or withdraw from the study at any time without any rationale. Informed oral consent was obtained from the patients relative, informed them that obtained data will not be included at any further researches without a second consent. Confidentiality and anonymity of each subject were ensured through coding of all data and protecting the obtained data.

\section{Study Procedure \\ Preparatory phase}

The current study was conducted by preparing of different data collection tools, in addition, obtaining formal paper agreement which was taken induration about two month duration before conducting the study and ended by carrying out the pilot study.

\section{Implementation phase}

Once the official permission is granted to proceed with the proposed study, the researcher initiated data collection by visiting the assigned settings on a daily basis during the day shifts. The enrolled patients and their relatives were informed individually about the purpose and nature of the study. Then, the researcher was obtained oral consent from those who accepted to participate in the study. Next, those patients were divided randomly into two equal groups; the researcher has started a collection of data from control group firstly by obtained patient's demographic and medical characteristic from patient file and their patient relatives and performed baseline physical assessment of the body systems (Tool 1) for enrolled patients on first day. The implementation time for this tool was (1-2 hours).

The control group patients were received routine hospital nursing care during the MV connection by critical care nurses that includes elevating the backrest of bed between $30^{\circ}-45^{\circ}$, daily sedation interruption and daily assessment of readiness to extubate, deep venous thrombosis prophylaxis and peptic ulcer prophylaxis. In addition used closed suctioning system, patient hygiene, enteral nutrition, drug administration and patient monitoring.

While data collection from study group was started after finishing from the control group, the researcher obtained patient's demographic and medical characteristic from patient file and their patient relatives and performed baseline physical assessment of the body systems (Tool 1) for enrolled patients on the first day. The implementation time for this tool was (1 2 hours). The study group patients were received modified ventilator bundle by the researcher with the cooperation of the medical and nursing staff.

Modified ventilator bundle are includes: head of bed elevation $30^{\circ}-45^{\circ}$ unless there is contraindicated, routine oral care applied three times per day (once every $8 \mathrm{hrs}$ ), early mobilization typically within 24-48 hours of ICU admission, endotracheal suctioning care using open suctioning system technique, daily sedation interruption and daily assessment of readiness to extubate to assessed patients for neurological recovery and readiness for extubation or resedated if required, deep venous thrombosis prophylaxis and used anti-embolic stockings, peptic ulcer prophylaxis, ventilator circuit care and maintaining of infection control measures to prevent nosocomial infections, in addition patient hygiene, enteral nutrition, drug administration and patient monitoring. Evaluation phase

After 72 hours at the fourth day of MV initiation, and the control group were received routine hospital nursing care by critical care nurses, and the study group were received the 
modified ventilator bundle by the researcher, the patients were started to be assessed for readiness to wean from the mechanical ventilator on a daily basis using weaning process assessment checklist (BWAP score) (Tool II) once every day till the patient extubated. The implementation time for this tool was (30-45 minutes).

\section{Statistical Analysis of Data}

Data were summarized, tabulated, and presented using descriptive statistics in the form of frequency distribution, percentages, means and standard deviations (SD) as a measure of dispersion. A statistical package for the social science (SPSS), version (22) was used for statistical analysis of the data, as it contains the test of significance given in standard statistical books. Numerical data were expressed as mean and SD. Qualitative data were expressed as frequency and percentage (\%). Chi-square, Fisher's and Pearson tests were used to compare frequencies and correlation between the study variables. Probability (P-value) is the degree of significance of the results was considered: ( $\mathrm{p}$ - value $>0.05)$ was considered not significant $(\mathrm{NS})$, (P-value $\leq 0.05)$ was considered significant $(\mathrm{S})$ and the (p-value $\leq 0.01)$ was considered highly significant (HS).

\section{Results}

Table (1): Comparison between study and control groups according to their demographic characteristic $(n=100)$.

\begin{tabular}{|c|c|c|c|c|c|c|}
\hline \multirow[b]{2}{*}{ Demographic data } & \multicolumn{2}{|c|}{ Study group $(n=50)$} & \multicolumn{2}{|c|}{ Control group $(n=50)$} & \multirow[t]{2}{*}{$\mathrm{X}^{2}$} & \multirow{2}{*}{$\begin{array}{c}\mathrm{P}- \\
\text { value }\end{array}$} \\
\hline & No. & $\%$ & No. & $\%$ & & \\
\hline Age / years & & & & & & \\
\hline $20-39$ & 11 & 22.0 & 6 & 12.0 & \multirow{3}{*}{2.937} & \multirow{3}{*}{$\begin{array}{l}.568 \\
\text { NS }\end{array}$} \\
\hline $40-59$ & 30 & 60.0 & 34 & 68.0 & & \\
\hline$\geq 60$ & 9 & 18.0 & 10 & 20.0 & & \\
\hline Mean \pm SD & \multicolumn{2}{|c|}{$48.1 \pm 11.3$} & \multicolumn{2}{|c|}{$51.1 \pm 9.8$} & & \\
\hline Gender & & & & & & \\
\hline Male & 32 & 64.0 & 35 & 70.0 & \multirow[t]{2}{*}{.407} & \multirow{2}{*}{$\begin{array}{l}.523 \\
\text { NS } \\
\end{array}$} \\
\hline Female & 18 & 36.0 & 15 & 30.0 & & \\
\hline Marital status & & & & & & \\
\hline Single & 3 & 6.0 & 1 & 2.0 & \multirow{3}{*}{1.245} & \multirow{3}{*}{$\begin{array}{l}.475 \\
\text { NS }\end{array}$} \\
\hline Married & 39 & 78.0 & 45 & 90.0 & & \\
\hline Widow & 8 & 16.0 & 4 & 8.0 & & \\
\hline Residence & & & & & & \\
\hline Urban & 19 & 38.0 & 14 & 28.0 & \multirow[t]{2}{*}{1.131} & \multirow{2}{*}{$\begin{array}{l}.288 \\
\text { NS } \\
\end{array}$} \\
\hline Rural & 31 & 62.0 & 36 & 72.0 & & \\
\hline Occupation & & & & & & \\
\hline Employee & 11 & 22.0 & 9 & 18.0 & \multirow{4}{*}{.756} & \multirow{4}{*}{$\begin{array}{l}.860 \\
\text { NS }\end{array}$} \\
\hline Worker/ farmer & 19 & 38.0 & 23 & 46.0 & & \\
\hline Housewife & 16 & 32.0 & 15 & 30.0 & & \\
\hline Retired & 4 & 8.0 & 3 & 6.0 & & \\
\hline Educational level & & & & & & \\
\hline Cannot read and write & 24 & 48.0 & 21 & 42.0 & \multirow{4}{*}{2.866} & \multirow{4}{*}{$\begin{array}{l}.581 \\
\text { NS }\end{array}$} \\
\hline Basic & 2 & 4.0 & 6 & 12.0 & & \\
\hline Secondary & 16 & 32.0 & 13 & 26.0 & & \\
\hline Bachelor & 8 & 16.0 & 10 & 20.0 & & \\
\hline
\end{tabular}

\section{NS = not significance}

Table (1): shows that, $(60.0 \%)$ of the study group compared with $(68.0 \%)$ of the control group their mean age ranged between $(48.1 \pm 11.3)$ and $(51.1 \pm 9.8)$ years respectively. As regards gender, $(64.0 \%)$ of the study group compared with $(70.0 \%)$ of the control group were males. According to marital status, (78.0\%) of the study group compared with (90.0\%) of the control group were married. Regarding residence, $(62.0 \%)$ of the study group compared with $(72.0 \%)$ of the control group lived in rural area, Related to their educational level, $(48.0 \%)$ of the study group compared with $(42.0 \%)$ of control group cannot read and write therefore the most of them were occupied as worker /farmer $(38 \%, 46 \%)$. Lastly, there were no statistically significance differences between study and control groups according to their demographic characteristic.

Table (2): Comparison between study and control groups according to their smoking habits and reason of ICU admission (n= 100).

\section{NS = not significance}

\begin{tabular}{|c|c|c|c|c|c|c|}
\hline \multirow[t]{2}{*}{ Items } & \multicolumn{2}{|c|}{$\begin{array}{c}\text { Study group } \\
(\mathrm{n}=50)\end{array}$} & \multicolumn{2}{|c|}{ Control group $(\mathrm{n}=50)$} & \multirow[t]{2}{*}{$\mathbf{X}^{2}$} & \multirow[t]{2}{*}{$\begin{array}{c}P- \\
\text { value }\end{array}$} \\
\hline & No. & $\%$ & No. & $\%$ & & \\
\hline \multicolumn{7}{|l|}{ Smoking habits } \\
\hline Smoker & 20 & 40.0 & 28 & 56.0 & \multirow[t]{2}{*}{2.564} & \multirow{2}{*}{$\begin{array}{l}.109 \\
\text { NS }\end{array}$} \\
\hline Not smoker & 30 & 60.0 & 22 & 44.0 & & \\
\hline \multicolumn{7}{|l|}{ Reason of ICU admission } \\
\hline Severe cardiac complain & 12 & 24.0 & 5 & 10.0 & \multirow{8}{*}{5.033} & \multirow{8}{*}{$\begin{array}{l}.656 \\
\text { NS }\end{array}$} \\
\hline Extremely respiratory complain & 5 & 10.0 & 7 & 14.0 & & \\
\hline Severe cerebrovascular complain & 5 & 10.0 & 6 & 12.0 & & \\
\hline Hemodynamic instability & 10 & 20.0 & 7 & 14.0 & & \\
\hline Traumatic injury & 4 & 8.0 & 6 & 12.0 & & \\
\hline Inhaled toxic substance & 4 & 8.0 & 5 & 10.0 & & \\
\hline Cardiac arrest & 6 & 12.0 & 8 & 16.0 & & \\
\hline Surgical emergencies & 4 & 8.0 & 6 & 12.0 & & \\
\hline
\end{tabular}


Table (2): illustrates that, $(60.0 \%)$ of the study group compared with (44.0\%) of the control group don't smoke. Regarding to reason of ICU admission, $(24.0 \%)$ of study group compared with $(10.0 \%)$ of the control group were admitted with severe cardiac complain. Lastly, there were no statistically significance differences between both studied groups according to their smoking habits and reason of ICU admission.

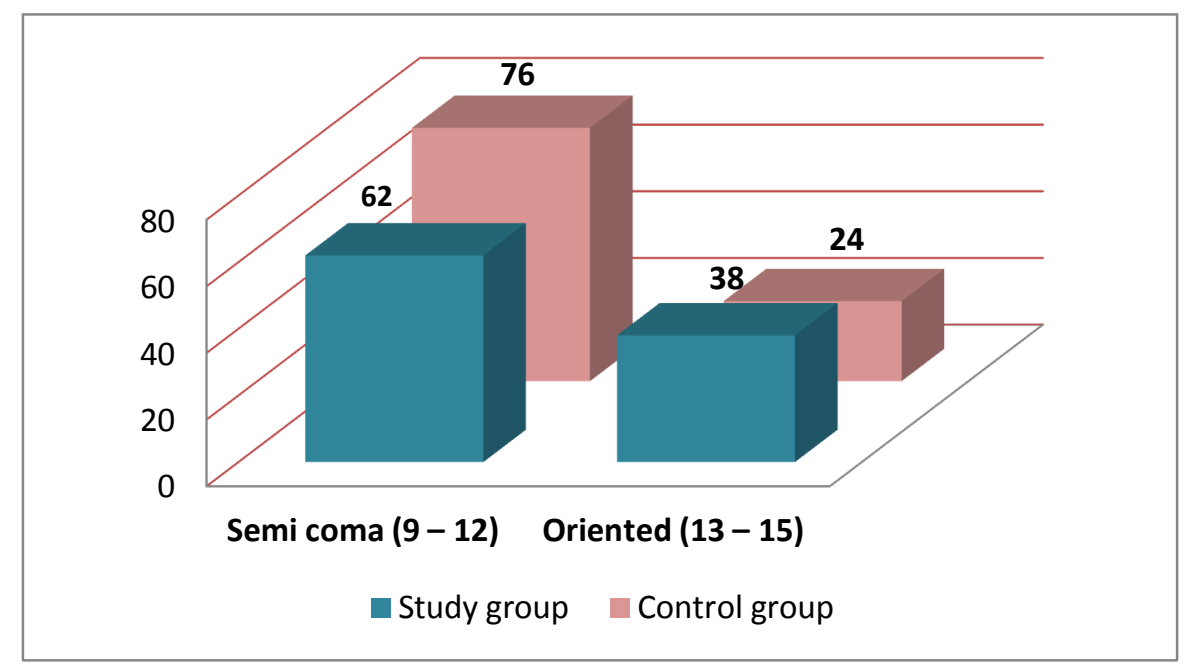

Figure (1): Percentage distribution of study and control groups according to their baseline physical assessment of neurological system according grades of GCS $(n=100)$.

Figure (1): illustrates that, $(62.0 \%)$ of the study group compared with $(76.0 \%)$ of the control group had a semi coma between (9-12), while (38.0\%) of the study group compared with (24.0\%) of the control group had oriented between (13-15).

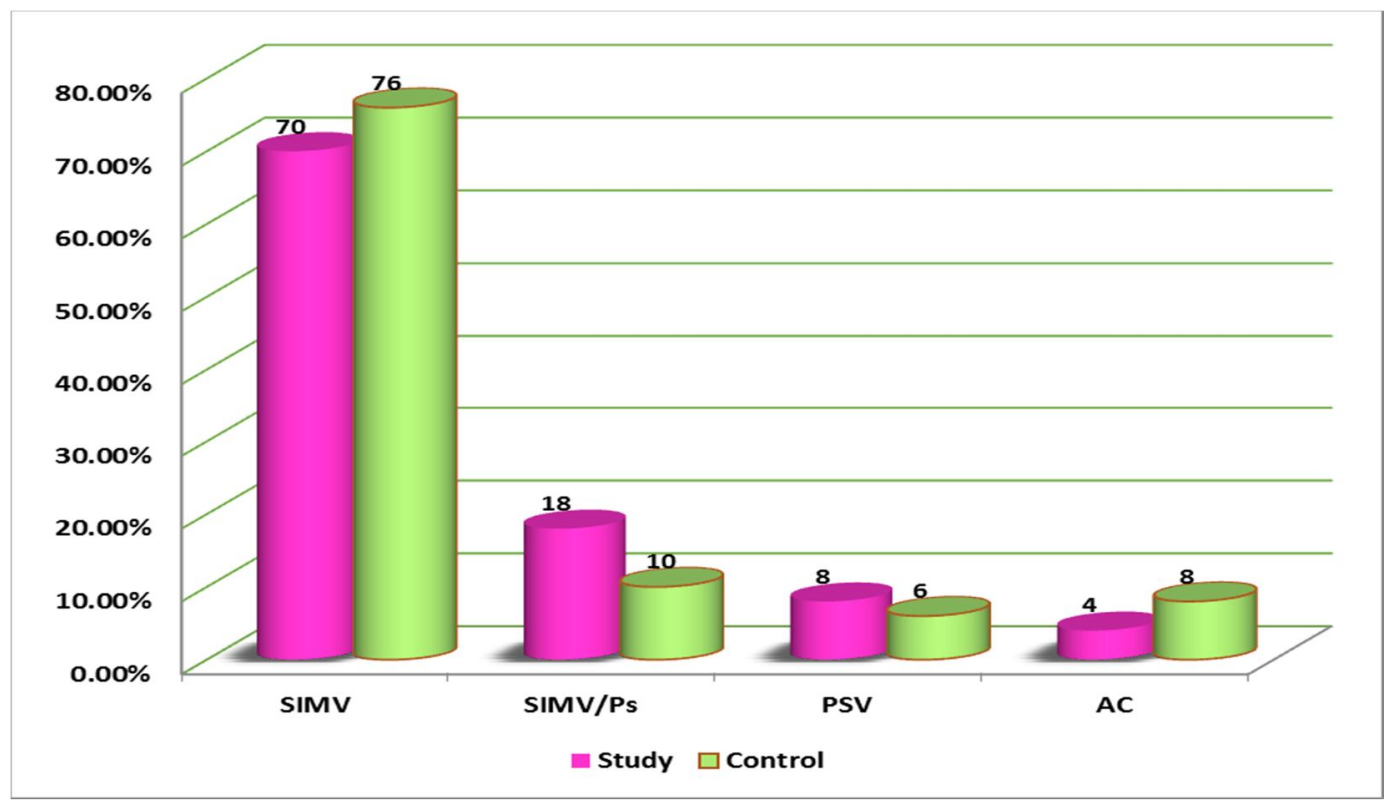

Figure (2): Percentage distribution of the study and control groups according to their initial mode of the mechanical ventilator $(\mathbf{n}=\mathbf{1 0 0})$.

Figure (2): illustrates that (70\%) of the study group compared to $(76 \%)$ of the control group on synchronized intermittent mandatory ventilation mode.

Table (3): Comparison between study and control groups according to their duration of mechanical ventilation / days after modified bundle implementation $(n=100)$.

\begin{tabular}{|c|c|c|c|c|c|c|}
\hline \multirow[t]{2}{*}{ Items } & \multicolumn{2}{|c|}{$\begin{array}{c}\text { Study group } \\
(\mathrm{n}=\mathbf{5 0 )}\end{array}$} & \multicolumn{2}{|c|}{$\begin{array}{l}\text { Control group }(\mathrm{n}= \\
\mathbf{5 0})\end{array}$} & \multirow[t]{2}{*}{$\overline{X^{2}}$} & \multirow[t]{2}{*}{$P$ - value } \\
\hline & No. & $\%$ & No. & $\%$ & & \\
\hline \multicolumn{7}{|c|}{ Duration of mechanical ventilation / days } \\
\hline $4-6$ days & 34 & 68.0 & 20 & 40.0 & \multirow[t]{2}{*}{7.890} & \multirow[t]{2}{*}{$.005 * *$} \\
\hline $7-9$ days & 16 & 32.0 & 30 & 60.0 & & \\
\hline Mean \pm SD & \multicolumn{2}{|c|}{$6.1 \pm 1.6$} & \multicolumn{2}{|c|}{$7.3 \pm 1.9$} & & \\
\hline
\end{tabular}

$* * \mathbf{P}-$ value $\leq \mathbf{0 . 0 1}$ 
Table (3) illustrates that, $(68.0 \%)$ of the study group, compared with only $(40.0 \%)$ of the control group had a shorter duration of mechanical ventilation support between (4- 6) days with mean \pm SD (6.1 \pm 1.6$)$ and (7.3 \pm 1.9$)$ respectively after modified bundle implementation with statistical significance differences $(\mathrm{P}-$ value .005$)$.

Table (4): Comparison between study and control groups according to their burns wean after modified bundle implementation at $1^{\text {st }}$ to $6^{\text {th }}$ observation $(n=100)$.

\begin{tabular}{|c|c|c|c|c|c|c|}
\hline \multirow[t]{2}{*}{ Total levels } & \multicolumn{2}{|c|}{$\begin{array}{c}\text { Study } \\
(n=50)\end{array}$} & \multicolumn{2}{|c|}{$\begin{array}{l}\text { Control } \\
(n=50)\end{array}$} & \multirow[t]{2}{*}{$\mathrm{X}^{2}$} & \multirow[t]{2}{*}{$\begin{array}{c}P \text { - } \\
\text { value }\end{array}$} \\
\hline & No. & $\%$ & No. & $\%$ & & \\
\hline $1^{\text {st }}$ observation (4 $\left.{ }^{\text {day }}\right)$ & & & & & & \\
\hline Unsuccessfully weaned & 21 & 42.0 & 37 & 74.0 & \multirow[t]{2}{*}{10.509} & \multirow[t]{2}{*}{$.001 * *$} \\
\hline Successfully weaned & 29 & 58.0 & 13 & 26.0 & & \\
\hline $2^{\text {nd }}$ observation ( $\left.5^{\text {day }}\right)$ & & & & & & \\
\hline Unsuccessfully weaned & 15 & 34.1 & 31 & 60.0 & \multirow[t]{2}{*}{9.232} & \multirow[t]{2}{*}{$.002 * *$} \\
\hline Successfully weaned & 29 & 65.9 & 16 & 34.0 & & \\
\hline 3rd observation (6 $\left.{ }^{\text {day }}\right)$ & & & & & & \\
\hline Unsuccessfully weaned & 8 & 30.8 & 17 & 44.7 & \multirow[t]{2}{*}{1.265} & \multirow[t]{2}{*}{$.05 *$} \\
\hline Successfully weaned & 18 & 69.2 & 21 & 55.3 & & \\
\hline $4^{\text {th }}$ observation $\left(7^{\text {day }}\right)$ & & & & & & \\
\hline Unsuccessfully weaned & 1 & 6.3 & 11 & 36.7 & \multirow[t]{2}{*}{5.007} & \multirow[t]{2}{*}{$.025^{*}$} \\
\hline Successfully weaned & 15 & 93.8 & 19 & 63.3 & & \\
\hline $5^{\text {th }}$ observation $\left(8^{\text {day }}\right)$ & & & & & & \\
\hline Unsuccessfully weaned & 0 & .0 & 4 & 17.4 & \multirow[t]{2}{*}{1.979} & \multirow[t]{2}{*}{$.159 \mathrm{NS}$} \\
\hline Successfully weaned & 10 & 100.0 & 19 & 82.6 & & \\
\hline $6^{\text {th }}$ observation $\left(9^{\text {day }}\right)$ & & & & & & \\
\hline Unsuccessfully weaned & 0 & .0 & 1 & 5.0 & \multirow[t]{2}{*}{.363} & \multirow[t]{2}{*}{$.547 \mathrm{NS}$} \\
\hline Successfully weaned & 7 & 100.0 & 19 & 95.0 & & \\
\hline
\end{tabular}

Table (4): shows that, $(58.0 \%)$ of the study group while $(26.0 \%)$ of the control group had successful weaning score at $4 \mathrm{t}^{\mathrm{h}}$ day , $(65.9 \%)$ of the study group while only $(34.0 \%)$ of the control group had successful weaning score at $5 \mathrm{t}^{\mathrm{h}}$ day , $(69.2 \%)$ of the study group but $(55.3 \%)$ of the control group had successful weaning score at $6^{\text {th }}$ day , $(93.8 \%)$ of the study group compared with only $(63.3 \%)$ of the control group had successful weaning score at $7^{\text {th }}$ day, $(100 \%)$ of the study group while $(82.6 \%)$ of the control group had successful weaning score at $8^{\text {th }}$ day and $(100 \%)$ of the study group while $(95 \%)$ of the control group had successful weaning score at $9^{\text {th }}$ day. there were statistically significance differences between the study and control groups in the $1^{\text {st }}, 2^{\text {nd }}, 3^{\text {rd }}$ and $4^{\text {th }}$ observation $(\mathrm{P}-$ value $\leq .001,002,05$ and .025$)$ respectively.

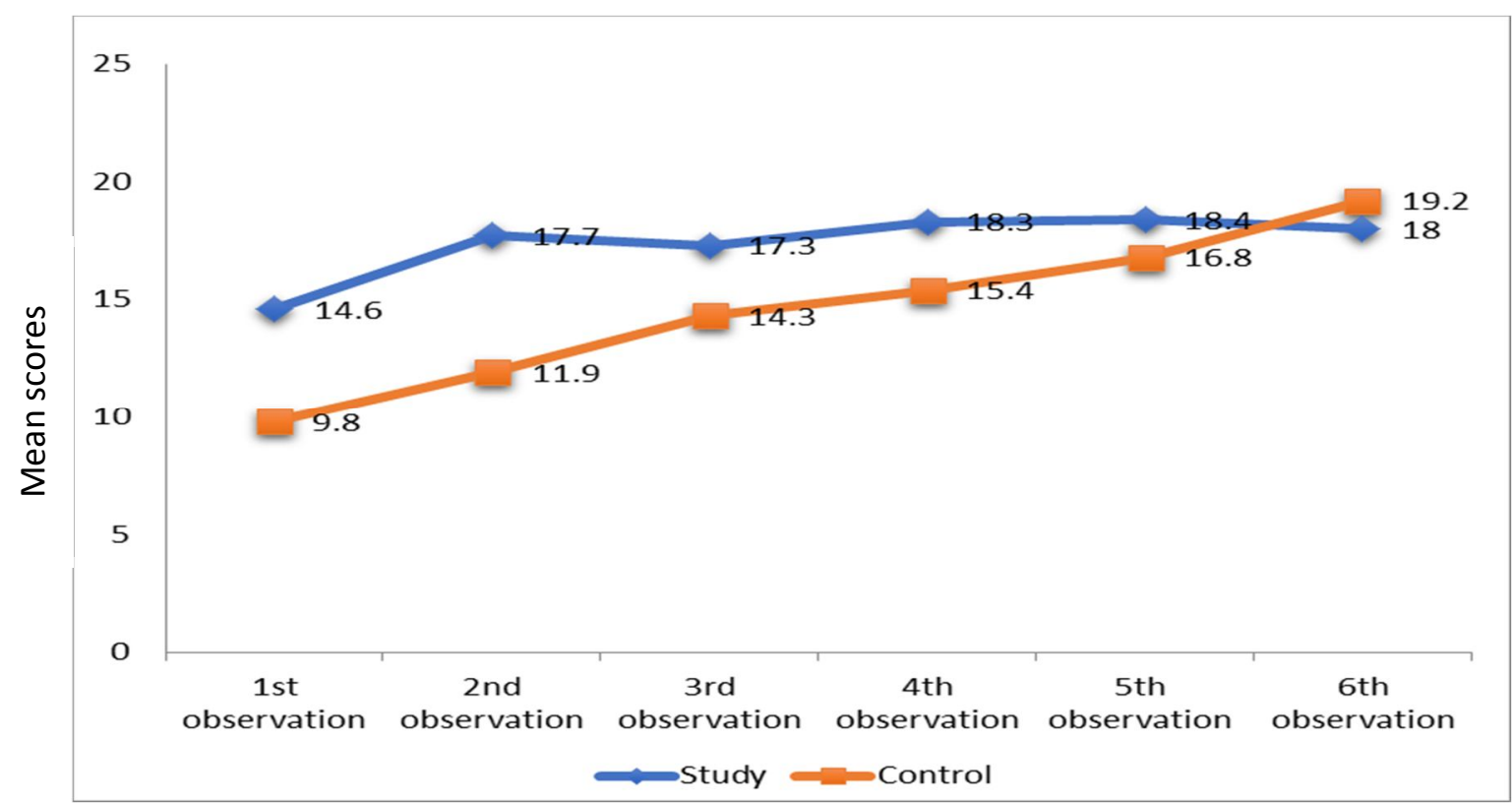

Figure (3): Means score of burns' wean assessment of the study and control group through six observations $(n=100)$

Figure (3): presents that, there were increase mean scores of burns' wean assessment in the study group than the control group; finding may have relevance to the effect after modified bundle implementation for the study group compared to routine hospital care . 
Table (5): Relation between study and control groups according to their weaned successfully and their smoking habits, and duration of MV at $1^{\text {st }}, 2^{\text {nd }}, 3^{\text {rd }}$ observation

\begin{tabular}{|c|c|c|c|c|c|c|c|c|c|c|c|c|}
\hline \multirow{3}{*}{ ITEMS } & \multicolumn{4}{|c|}{$1^{\text {st }}$ observation } & \multicolumn{4}{|c|}{$2^{\text {nd }}$ observation } & \multicolumn{4}{|c|}{$3^{\text {rd }}$ observation } \\
\hline & \multicolumn{2}{|c|}{$\begin{array}{l}\text { Study } \\
(\mathrm{n}=29)\end{array}$} & \multicolumn{2}{|c|}{$\begin{array}{l}\text { Control } \\
(n=13)\end{array}$} & \multicolumn{2}{|c|}{$\begin{array}{l}\text { Study } \\
(n=29)\end{array}$} & \multicolumn{2}{|c|}{$\begin{array}{l}\text { Control } \\
(\mathrm{n}=16)\end{array}$} & \multicolumn{2}{|c|}{$\begin{array}{l}\text { Study } \\
(n=18)\end{array}$} & \multicolumn{2}{|c|}{$\begin{array}{l}\text { Control } \\
(\mathrm{n}=21)\end{array}$} \\
\hline & No. & $\%$ & No. & $\%$ & No. & $\%$ & No. & $\%$ & No. & $\%$ & No. & $\%$ \\
\hline Smoking habits & & & & & & & & & & & & \\
\hline Smoker & 9 & 31.0 & 3 & 23.1 & 11 & 37.9 & 13 & 81.3 & 7 & 38.9 & 12 & 57.1 \\
\hline Not smoker & 20 & 69.0 & 10 & 76.9 & 18 & 62.1 & 3 & 18.7 & 11 & 61.1 & 9 & 42.9 \\
\hline $\mathrm{X}^{2}(\mathrm{P}-$ value $)$ & \multicolumn{4}{|c|}{$10.951\left(.001^{* *}\right)$} & \multicolumn{4}{|c|}{$11.978(.001 * *)$} & \multicolumn{4}{|c|}{$3.386\left(.05^{*}\right)$} \\
\hline \multicolumn{5}{|c|}{ Duration of mechanical ventilation } & & & & & & & & \\
\hline 4- 6 days & 28 & 96.6 & 12 & 92.3 & 27 & 93.1 & 15 & 93.7 & 10 & 55.6 & 8 & 38.1 \\
\hline 7- 9 days & 1 & 3.4 & 1 & 7.7 & 2 & 6.9 & 1 & 6.3 & 8 & 44.4 & 13 & 61.9 \\
\hline $\mathrm{X}^{2}(\mathrm{P}-$ value $)$ & \multicolumn{4}{|c|}{$49.575(.05 *)$} & \multicolumn{4}{|c|}{$68.580(.0001 * *)$} & \multicolumn{4}{|c|}{$16.054(.0001 * *)$} \\
\hline
\end{tabular}

Table (5): shows that, there were statistically significance difference between both study and control groups in the $1^{\text {st }}, 2^{\text {nd }}$ and $3^{\text {rd }}$ observation of successfully weaning regarding to their smoking habits and duration of mechanical ventilator connection and successful weaning $(\mathrm{P}-$ value $\leq .001, .05 .001, .0001,05$ and .0001$)$ respectively

\section{Discussion}

Institute for Healthcare Improvement developed the concept of "ventilator care bundles" to help health care providers more reliably deliver the best possible care for patients undergoing particular treatments with inherent risks. The modified ventilator bundle is considered as a "package" of evidence-based guidelines, designed to reduce in VAP rates, improvement of weaning strategies and promote adherence to evidence-based protocols and guidelines in order to improve clinical outcomes (Alsoda. et al., 2020).

Therefore, the current study was conducted aimed to apply a modified ventilator bundle and evaluate its effect on weaning among mechanically ventilated patients.

Regarding demographic characteristics of the studied samples, the current study showed that, nearly two third of the study and control groups their mean age \pm SD between $(48.1 \pm$ $11.3)$ and $(51.1 \pm 9.8)$ years respectively. Finding of the current study explain by the researcher points of view that, most people above forty year, they are more risk to expose of many health problems such as cardiac / respiratory/ kidney/ hepatic and neurological disease due to ageing process and physiological changes.

This finding is consistent with Kasem, .et al., (2019), they studied about the "Recent predictive parameters for successful weaning from mechanical ventilation in critically ill patients" the study showed that, there was no statistically significance difference between the study and control groups according to their age, mean age \pm SD between $(47.86 \pm$ $15.94)$ and (47.41 \pm 1564$)$ years respectively. In contrasting with the current study finding the study done by Faramarzi, (2020), who evaluate the "Effect of gastric residual volume monitoring on incidence of ventilator-associated pneumonia in mechanically ventilated patients admitted to intensive care unit" the study found that, the majority of the studied patients more than 60 years old with mean age \pm SD between $(59.72 \pm$ 19.01) years.

As regards gender, the current study found that, more than two-thirds of the study and control groups were males. Finding of the current study explain by the researcher points of view that; males have greater risk than females due to high levels of calcification in their arteries in addition highly

$P$ a g e | 127 exposure to occupational hazards, stresses and frequent use of cigarettes and hookahs.

The study finding was consistent with Ghiani. et al., (2020), they studied "Variables predicting weaning outcome in prolonged mechanically ventilated tracheotomized patients" the study showed that, male represent more than two-thirds in cases with both weaning success and weaning failure groups. In contrary with the current study finding the study done by Alkotami, .et al., (2019); who studied "Prognostic factors of patients were requiring ventilatory support in the neurointensive care unit" the study found that, more than half of the studied patients were females.

Regarding to smoking habits, the current study illustrated that, nearly half of the study and control groups were smoker with no statistically differences between both studied groups. Finding of the current study explain by the researcher points of view that; smoking increases the risk for developing more serious health problems as lung failure/cancer, heart disease and stroke and may increase the risk of developing pneumonitis, also smoking causes oxidant stress, inflammation, and protease-anti-protease imbalance of the lung tissue Therefore, they need to use a ventilation support for life saving intervention.

This result was conformity with the study conducted by Fortaleza, et al. (2020), who studied the "Sustained reduction of healthcare-associated infections after the introduction of a bundle for prevention of ventilatorassociated pneumonia in medical-surgical intensive care units" who said that smoking are one of most risk factors associated with developed of VAP among mechanical ventilated patient. Also study finding opposite with Liu, .et al. (2020), who studied "Evaluation of the effects of applying the ventricular care bundle (VCB) method for reducing ventilator-associated pneumonia (VAP) in the intensive care unit of general Chinese hospital" illustrated that, there highly statistically differences between the intervention and control groups related to smoking habits.

On comparing the study and control groups by their reason of ICU admission, nearly half of study and control groups the main reason were cardiorespiratory disease .Finding of the current study explain by the researcher points of view that; respiratory and cardiac problems are the leading causes for compromising normal ventilation process, Amany S., et al 
pulmonary circulation, and lunge compliance of the human body and hence they are the most common diagnosis among the mechanical ventilated patients.

This result was conformity with the study conducted by Karagozoğlu, et al., (2018), who studied "The Effect of bundle adaptation control on VAP speed and length of hospital stay in avoiding the ventilator associated pneumonia (VAP) at anesthesia intensive care unit" they found, the most of the controlled and uncontrolled groups the main reason of ICU admission were internal medical diseases. One the other hand the present study finding was disagreement with Lee, et al., (2016), who studied "The importance of tracheostomy to the weaning success in patients with conscious disturbance in the respiratory care center" they showed that, less than half of the first and second groups the most reasons for patient's admission were neurological disease.

On comparing the study and control groups by their baseline neurological assessment according grades of GCS, the current study illustrated that, two thirds of the study group compared with almost three quarters of the control group were semi coma and more than one thirds of the study group while only quarters of the control group had oriented with statistical significant difference with ( $\mathrm{P}$ - value .027). Finding of the current study explain by the researcher points of view that; patients had higher GCS scores indicating that patients who had a stable condition were more likely to achieve favorable weaning outcomes and short duration of MV connection than those who did not.

The current study consistent with Cinotti, et al., (2018), they studied "Management and weaning from mechanical ventilation in neurologic patients" they found that, the majority of patients which predictors of successful extubated had semi coma GCS $>10$. The current study finding was contrasting with the study conducted by Okabe, (2018), who studied "Risk factors for prolonged mechanical ventilation in patients with multiple injuries and blunt chest trauma " who showed, nearly one third of both SMV and PMV groups were higher rate of severe GCS $(\leq 8)$ with significantly difference (P- value 0.047).

According to their baseline physical assessment of respiratory system, as regards initial ventilated mode, the result showed that, the majority of both study and control groups were connected with SIMV mode. Finding of the current study explain by the researcher points of view that; because SIMV mod the patients are partial dependent on MV, the ventilator breath are synchronized with patient inspiratory effort and has been described as the most effective and efficient mode of ventilation especially in the ICU .This will encourage use of patients' respiratory muscles, facilitate spontaneous breathing trials and this in turn would and enhance early weaning".

The current study finding was consistent with AbdElbaky, Mohammed, (2020), they studied " Effect of various body positions on the measurement of endotracheal tube cuff pressure among critical patients" they found, all of the studied patients, remained attached to the mechanical ventilator on SIMV mode during the MV connection. On the other hand, the present study finding was opposite with Al-Banna, et al., (2016), who studied "Mechanical ventilation relationship between body mass index and selected patients outcomes at a university hospital in Cairo" they stated that, more than three quarters of the studied groups were received continuous mandatory ventilation (CMV) mode.
Regarding the comparison between the study and control groups by their duration of mechanical ventilator in days, the current study finding illustrated that, more than two third of the study group, while only less than half of the control group were staying on MV for shorter duration (4- 6 days), and nearly one third of the study group compared with more than half of control group were staying on ventilation support for longer duration (7- 9) days with statistical significant difference between both studied groups $(\mathrm{P}-$ value $.005)$, mean length of stay \pm SD between $(6.1 \pm 1.6)$ and $(7.3 \pm$ 1.9) respectively. Finding of the current study explain by the researcher points of view: implementation of modified ventilator bundle practices may reduce the incidence of such complication, improve the quality of patient care, improve the prognosis of patient condition and this in turn would decrease the average length of ventilation support and hospital length of stays.

The current study agreement by Alsoda, et al., (2020), they studied "Implementation of ventilator bundle for prevention of ventilator-associated pneumonia in intensive care unit" they found, significant reduction the length of MV after implementation of ventilator bundle the whole mean ventilation duration was ( $10 \pm 89$ days $)$ for both groups. Also current study consistent with Wolfensberger, et al., (2020), they studied "Implementation and evaluation of a care bundle for prevention of non-ventilator associated hospital-acquired pneumonia - a mixed-methods study protocol for a hybrid type 2 effectiveness implementation trial" they found that, most of the test group has got a shorter length of MV connection after application of VAP bundle with statistical significant difference.

In relation to weaning scores the current study finding showed that, the study group that utilized the full individual components of modified ventilator bundle obtained higher weaning scores compared with the control group who did not utilize all individual elements together with the statistical significant difference was detected between both groups in the $1^{\text {st }}, 2^{\text {nd }}, 3^{\text {rd }}$ and $4^{\text {th }}$ observation $(\mathrm{P}-$ value $\leq .001$, 002, 05 and .025).

The current study finding was supported by Jeong \& Lee, (2018), they studied "Clinical application of modified burns wean assessment program scores at first spontaneous breathing trial in weaning patients from mechanical ventilation" they found, study group were significantly higher rate of successful weaning scores compared with the control group after applying of VAP bundles. On the same line, the current study was agreement with Lavallée, et al. (2019), studied "The effects of care bundles on patient outcomes: a systematic review and Meta -analysis" they found, application of ventilator bundles practices in the study group associated with positive effect on patients outcomes include higher rate of successful weaning scores, reduction in mortality rate and length of stay.

Regarding the relationship between study and control groups according to their weaned successfully and their smoking habits, duration of MV at the different observations, the study represented that, there were statistically significance difference between both study and control groups in the 1st, 2nd and 3rd observation of successfully weaning regarding to their smoking habits and duration of mechanical ventilator connection and successful weaning $(\mathrm{P}-$ value $\leq .001, .05$ $.001, .0001,05$ and .0001$)$ respectively . Finding of the current study explain that: the study group of patient was received the modified ventilator bundle practices can significantly attribute 
in successful patients weaning from $\mathrm{MV}$, and this in turn reduction the duration of ventilation support than the control group.

Current study was consistent with Al-Thaqafy, et al, (2018), who studied "Association of compliance of ventilator bundle with incidence of ventilator-associated pneumonia and ventilator utilization among critical patients over 4 years" they found, significant correlation between both studied groups as regards successfully weaning regarding to their smoking habits and duration of MV connection.

\section{Conclusion}

Based on current study results and research hypothesis, the following can be concluded that: The study group of patients who received the complete modified ventilator bundle had higher weaning scores and shorter duration of mechanical ventilator compared with the other control group of patients who received routine hospital nursing care.

\section{Recommendations \\ Recommendations related to nurses}

\section{References}

(1) Abd -Elbaky, M. M., Mohammed, E. F., (2020). Effect of various body positions on the measurement of endotracheal tube cuff pressure among critical patients. International Journal of Novel Research in Healthcare and Nursing, 7, (3), (42-50).

(2) Ahmed, R. Q., Sobeih, H. S., \& Abdelsalam, S. N. (2019). Ventilator Associated Pneumonia Bundle among Mechanically Ventilated Patient: Nurses' Perception. (Master Degree), Medical Surgical Nursing (Critical Care Nursing), Ain Shams University.

(3) Al-Banna, M. M., Morsy, W. Y. M., El-Feky, H. A., \& Abdelmohsen, A. H. (2016). Mechanical Ventilation: Relationship between Body Mass Index and Selected Patients' Outcomes at a University Hospital in Cairo. Reserach Gate, 1-14.

(4) Alkotami, A. S., Rashed, K. H., Ragab, M. A., \& Nassara, H. G. (2019). Prognostic factors of patients requiring ventilatory support in the neurointensive care unit. Tanta Medical Journal, 46 (3), 10-18.

(5) Alsharari, A. F., Aroury, A. M., Dhiabat, M. H., Alotaibi, J. S., Alshammari, F. F., Alshmemri, M. S., \& Alnawwar, M. A. (2020). Critical care nurses' perception of care coordination competency for management of mechanically ventilated patients. Journal of Clinical nursing 29(7), 1341.

(6) Alsoda, M. F., Al-Shahat, M. M., Reda, S. M. K., Alsawah, A. Y., Abboud, M. A. M., \& Elgendy, A. E. (2020). Implementation of ventilator bundle for prevention of ventilator-associated pneumonia in pediatric intensive care unit. Journal of Medicine in Scientific Research, 2(1), 265-272.

(7) Al-Thaqafy, M. S., El-Saed, A., Arabi, Y. M., \& Balkhy, H. H. (2018). Association of compliance of ventilator bundle with incidence of ventilatorassociated pneumonia and ventilator utilization among critical patients over 4 years. Thoracic medicine, 9(4), 221-226.

(8) Burns SM, Burns JE, Truwit JD\& Orso, D. (1990). Comparison of five clinical weaning indices. Am Journal Crit Care. 1990; 3:3 42-52.

(9) Cinotti, R., Bouras, M., Roquilly, A., \& Asehnoune, K. (2018). Management and weaning from mechanical ventilation in neurologic patients. Annals of Translational Medicine, 19(6), 381-390.

(10) Faramarzi, E., Mahmoodpoor, A., Hamishehkar, H., Shadvar, K., Iranpour, A., Sabzevari, T., \& Sanaie, S. (2020). Effect of gastric residual volume monitoring on incidence of ventilator-associated pneumonia in mechanically ventilated patients admitted to intensive care unit. Pak J Med Sci., 36(2), 4853.

(11) Fortaleza CM, et al. (2020). Sustained reduction of healthcare-associated infections after the introduction of a bundle for prevention of ventilatorassociated pneumonia in medical-surgical intensive care units. Braz J Infect Dis.

(12) Ghiani, A., Paderewska, J., Sainis, A., Crispin, A., Walcher, S., \& Neurohr, C. (2020). Variables predicting weaning outcome in prolonged mechanically ventilated tracheotomized patients: retrospective study. Journal of Intensive Care, 8(19), 2-10.

(13) Jeong, E. S., \& Lee, K. (2018). Clinical Application of Modified Burns Wean Assessment Program Scores at First Spontaneous Breathing Trial in Weaning Patients from Mechanical Ventilation. Acute and Critical Care, 33(4), 260-268.
(1) Designing in-service training educational program for critical care nurses to improve nurses' knowledge and practice regarding modified ventilator bundle.

(2) Strict supervision and follow up of nurses' compliance with modified ventilator bundle application with their patients.

(3) Developing a simplified and comprehensive booklet including basic information about VAP as; definition, risk factor and nursing role towards VAP prevention, components of modified ventilator bundle and its importance.

\section{Recommendations related to patients}

(1) Applying the grouped ventilator bundle practices together in a full compliance for the mechanically ventilated patients.

(2) Modified ventilator bundle should be replicated on multiple types of diagnosis among mechanically ventilated patient.

\section{Recommendations for furthers researches}

(1) Replication of the study on a larger probability sample from different geographical locations in Egypt to ensures the generalizability of the study.

(14) Karagozoğlu Ș, Yildiz FT, Gursoy S, Gulsoy Z, Suha BK, et al. (2018) The Effect of Bundle Adaptation Control on VAP Speed and Length of Hospital Stay in Avoiding the Ventilator Associated Pneumonia (VAP) at Anesthesia Intensive Care Unit. Int J Nurs Clin Pract 5: 295. https://doi.org/10.15344/2394-

(15) Kasem, O. A.-H., Abdel- Galeel, A. M., Abdel -Gawad, M., El- Suod, A.-H A., \& Hemdan, A. H. E.-S. (2019). Recent Predictive Parameters for Successful Weaning from Mechanical Ventilation in Critically Ill Patients. Egyptian Journal of Hospital Medicine, 75 (3), 2426-2432.

(16) Krishnappa, S., J. M. Rachaiah, S. Hegde, K. S. Sadananda, M. C. Nanjappa, G. Ramasanjeevaiah and R. C. Kanakalakshmi (2018).High Risk Parahisian Pathways-Mid Septal and Anteroseptal: Feasibility, Advantages, Safety and Outcomes of Alternate Site Approach-A Single Centre Study." Journal of Cardiovascular Disease Research $9(2)$

(17) Lavallée, J. F., Gray, T. A., Dumville, J., Russell, W., \& Cullum, N. (2019) The effects of care bundles on patient outcomes: a systematic review and meta-analysis. Implement, 142(12).

(18) Lee, Y.-C., Wang, H.-C., Hsu, C.-L., Wu, H.-D., Hsu, H.-S., \& Kuo, C.-D (2016), the importance of tracheostomy to the weaning success in patients with conscious disturbance in the respiratory care center. Journal of the Chinese Medical Association, 79 (6), 72-76.

(19) Liu W, Yang Y, Jiao Y, Zhang K, Hai Y, Li H, Xing H, Xu B, Bai H, Zhao Y, Bao H, Zhang S, Ren W, Yang L, Yang H, Wang M, Guo T. (2020) Evaluation of the effects of applying the ventricular care bundle (VCB) method for reducing ventilator-associated pneumonia (VAP) in the intensive care unit of a general Chinese tertiary hospital. Ann Palliat Med: 10.21037/apm-20-289

(20) Mart, M. F., Brummel, N. E., \& Ely, E. W. (2019). The ABCDEF Bundle for the Respiratory Therapist. Journal of Respiratory Care, 64 (12), 15611573.

(21) Okabe, Y. (2018). Risk factors for prolonged mechanical ventilation in patients with severe multiple injuries and blunt chest trauma: a single center retrospective case-control study. Acute Medicine \& Surgery, 5(1), 166-172.

(22) Schulz, C (2019). Implementation of a Ventilator Associated Pneumonia Prevention Bundle in the Emergency. (Doctor of Nursing Practice Degree), University of Maryland School of Nursing, Pro Quest.

(23) Usadọlo, QE. (2016). The impact of social exchange on volunteers workplace outcomes in non-profit organisations. School of business and tourism southern cross university. $\mathrm{PhD}$ thesis of Philosophy.Available at https: //epubs. scu.edu.au/ cgi/ viewcontent. cgi? article $=1548$ \& context=theses.

(24) Vetrugno, L., Guadagnin, G. M., Brussa, A., Orso, D., Garofalo, E., Bruni, A., . . . Bove, T. (2020). Mechanical ventilation weaning issues can be counted on the fingers of just one hand: part 1. Ultrasound Journal, 12(9), 2 10.

(25) Wolfensberger, A Clack1, L Stefanie, v. F Kusejko, K, Hesse, M. F , Jakob, W. . . . Sax, H. (2020). Implementation and evaluation of a care bundle for prevention of non-ventilator associated hospital-acquired pneumonia (nvHAP) - a mixed-methods study protocol for a hybrid type 2 effectiveness implementation. BMC Infectious Diseases, 603 (20), 1-11. 